\title{
DEMOCRACIA, PARTICIPAÇÃO E MUDANÇA GERACIONAL NO BRASIL
}

\author{
DEMOCRACY, PARTICIPATION AND GENERATIONAL CHANGE IN BRAZIL
}

Ednaldo Aparecido Ribeiro ${ }^{1}$

Carla Simara Ayres ${ }^{2}$

\section{RESUMO}

Por meio de análise quantitativa de dados produzidos pelo projeto World Values Surveys, o artigo pretende identificar o impacto que o período de vigência de instituições democráticas em nosso país produziu sobre as faixas etárias mais jovens da população, que tiveram suas experiências de socialização política sob tal forma de governo. Partindo do pressuposto de que a incorporação de valores e atitudes que subsidiam os comportamentos políticos individuais ocorre principalmente nas duas primeiras décadas de vida do indivíduo, procuramos verificar a validade da hipótese de que as instituições democráticas e as experiências que as mesmas proporcionam tenderiam a favorecer o estabelecimento de disposições mais participativas entre o público nacional mais jovem. Para tanto, foram empregados testes de associação entre uma variável que distingue diferentes grupos etários e algumas medidas sobre participação em diferentes modalidades de participação política.

Palavras-chave: Participação convencional. Participação não convencional. Mudança geracional. Socialização. Democracia.

1 Professor do Departamento de Ciências Sociais da Universidade Estadual de Maringá, e-mail para contato: ednaldorip@uol.com.br.

2 Graduanda do curso de Ciências Sociais na Universidade Estadudal de Maringá e bolsista de Iniciação Científica - PIBIC/Cnpq, e-mail para contato: carlazzl@hotmail.com. 


\begin{abstract}
Through quantitative analysis of data produced by the project World Values Surveys, the paper aims to identify the impact that the duration of democratic institutions in our country had on the younger age groups of the population who have had their political socialization during this form of government. Assuming that the incorporation of values and attitudes that support individual political behavior occurs mainly in the first two decades of life of individuals, seek to verify the validity of the hypothesis that democratic institutions and the experiences they provide tend to favor the establishment of more participatory arrangements between the national audience younger. For this, we have tested the association between a variable that distinguishes different age groups and some policy on participation in different forms of political participation.
\end{abstract}

Key-Words: Conventional participation. Non-conventional participation. Generational change. Socialization. Democracy.

\title{
INTRODUÇÃO
}

Mesmo diante do avanço de concepções minimalistas sobre a democracia, inspiradas no modelo proposto por Joseph Schumpeter (1961), a participação continua ocupando posição relevante na agenda de pesquisas da ciência política contemporânea. Ainda que as bases das democracias concretamente existentes se localizem sob as instituições representativas, há atualmente relativo consenso sobre a relevância de algum nível de envolvimento dos cidadãos nos assuntos públicos. Mesmo diante da impossibilidade de participação plena e direta, alguma dose de ativismo político continua sendo fundamental para o controle e a fiscalização das autoridades políticas.

A persistência dessa relevância tem sido recorrentemente confirmada pelos inúmeros estudos que nas últimas décadas têm buscado definir conceitualmente a participação, construir tipologias e também identificar os determinantes do envolvimento em termos individuais e societais. No que se refere a esse segundo objetivo, tem sido aceita uma divisão entre formas tradicionais ou convencionais e contestatórias ou não convencionais. No primeiro grupo estariam as ações ligadas ao sistema representativo, como o ato de votar e o envolvimento em partidos políticos (Norris, 2007). O segundo grupo seria composto por formas de ativismo contestatório às elites políticas e às próprias instituições tradicionais, tais como a assinatura de abaixo-assinados, petições, participação em passeatas, boicotes, ocupações de edificações, dentre outras (Inglehart \& Welzel, 2005; Norris, 2007).

No campo das pesquisas empíricas podem ser encontrados fortes indícios do declínio ou da estabilização das formas convencionais (Dalton \& Wattenberg, 2001, Putnam, 2003) e da ampliação das não convencionais (Della Porta, 2003; Inglehart \& Catterberg, 2002; Norris, 2007; Welzel, Inglehart \& Deutsch, 2005; Catterberg, 2004).

A partir da identificação desse quadro em nível mundial, duas explicações distintas têm sido propostas quanto aos seus potenciais efeitos sobre os processos de consolidação e aprofundamento de sistemas democráticos. De um lado temos aqueles que, preocupados com o declínio do engajamento cívico e com a ampliação do descontentamento, veem o risco desses fenômenos provocarem a erosão parcial das bases sociais e culturais imprescindíveis para o bom funcionamento dessa forma de governo (Putnam, 2003; Putnam \& Goss, 2003). Por outro lado, localizamos autores afirmando que a ampliação da contestação estaria relacionada à adoção de valores pós-materialistas e ao surgimento de uma cidadania crítica congruente com o aprofundamento democrático (Norris, 2002; Welzel, Inglehart \& Deutsch, 2005; Inglehart \& Welzel, 2005).

Século XXI, UFSM, Santa Maria, v. 1, n. 2, p. 62-78, jul./dez. 2011 
No que diz respeito aos condicionantes e determinantes, as investigações têm apontado para a relevância de variáveis relacionadas à centralidade social dos indivíduos. Milbrath \& Goel (1965), por exemplo, ressaltam que níveis mais elevados de participação podem ser encontrados naqueles com maior escolaridade, nos provenientes das classes médias, nos homens em relação às mulheres, naqueles com idade intermediária, nos casados, nos que moram nas cidades em relação aos que moram no campo, nos que moram há muito tempo num lugar em relação aos que acabam de se transferir, nas maiorias étnicas, naqueles engajados socialmente. Verba e Nie (1972), e Verba, Schlozman e Brady (1995) identificaram também, através de pesquisas comparadas, uma correspondência entre status social e participação.

Sem questionar a relevância dessa explicação, no presente trabalho pretendemos enfatizar o que consideramos ser também um fator fundamental para o estabelecimento de atitudes e disposições participativas: a socialização política. Acreditamos que seja plausível supor que as diferentes experiências por que passam os distintos grupos geracionais ou etários possam ser relevantes para a explicação dos níveis de envolvimento político, tanto convencional como contestatório. Sem desprezar, portanto, variáveis de natureza socioeconômicas, nossa intenção é testar no plano empírico a hipótese de que as diferentes gerações apresentam níveis distintos de participação política em razão das suas experiências específicas de socialização. Mais especificamente, procuramos testar se no cenário brasileiro existem diferenciais significativos em indicadores de envolvimento político entre estratos populacionais que passaram por diferentes experiências políticas em razão da sua vivência sob contextos institucionais distintos.

Para atingir esse objetivo dividimos o trabalho em três partes fundamentais. Na primeira delas aprofundamos alguns elementos teóricos importantes sobre a questão da participação e sobre a relevância das experiências de socialização para a formação das orientações políticas dos indivíduos. Na sequência, tecemos breves considerações metodológicas sobre os procedimentos empregados na investigação. Por fim, apresentamos e discutimos os resultados encontrados.

\section{PARTICIPAÇÃO, MUDANÇA GERACIONAL E EXPERIÊNCIAS POLÍTICAS}

Uma primeira aproximação do conceito de participação no contexto dos sistemas políticos contemporâneos nos remete à questão da influência ou do desejo de influenciar os processos decisórios que resultam na distribuição dos bens e recursos públicos (Booth \& Seligson, 1978; Axford, 1997).

A operacionalização dessa influência pode ocorrer de diferentes maneiras e uma listagem sobre as suas modalidades nunca será completa ou exaustiva. Milbrath e Goel (1965), em um dos primeiros esforços de sistematização nessa direção, propõem a seguinte classificação em termos de crescente complexidade e custos envolvidos: expor-se a solicitações políticas, votar, participar de discussões políticas, tentar convencer alguém a votar de determinado modo, usar um distintivo político, fazer contato com funcionários públicos, contribuir com dinheiro a um partido ou candidato, assistir a um comício ou assembleia, dedicar-se a uma campanha política, ser membro ativo de um partido político, participar de reuniões onde se tomam decisões políticas, solicitar contribuições em dinheiro para causas políticas, candidatar-se a um cargo eletivo, ocupar cargos públicos.

Todos esses comportamentos, todavia, relacionam-se apenas ao que podemos denominar de formas de atuação socialmente aceitas ou convencionais. A revisão da literatura sobre o tema revela que durante décadas os pesquisadores se debruçaram exclusivamente sobre essas 
modalidades (Almond \& Verba, 1963; Verba \& Nie, 1972). Como argumenta criticamente Norris (2007, p. 639):

\begin{abstract}
Citizen-oriented activities, exemplified by voting participation and party membership, obviously remain important for democracy, but today this represents an excessively narrow conceptualization of activism that excludes some of the most common targets of civic engagement which have become conventional and mainstream.
\end{abstract}

A partir da emergência dos chamados novos movimentos sociais na década de 1960, a relevância de atividades que escapam à classificação convencional se tornou evidente. Esses movimentos trouxeram à tona formas de engajamento político orientadas por causas específicas com acentuado conteúdo de protesto. Della Porta (2003) elenca algumas das formas pelas quais essa participação não convencional tem se expressado: escrever a um jornal, aderir a um boicote, autorreduzir impostos ou rendas, ocupar edifícios, bloquear o trânsito, assinar uma petição, fazer um sit-in, participar de uma greve, tomar parte em manifestações, danificar bens materiais, utilizar violência contra pessoas.

Para explicar os níveis individuais e societais de envolvimento tanto nas formas convencionais quanto nas convencionais, diferentes abordagens têm sido propostas. Talvez, uma das primeiras iniciativas nesse sentido seja a de Milbrath e Goel (1965), produzida a partir de estudos empíricos conduzidos nos Estados Unidos. Como já apontamos na introdução, as conclusões desse pesquisador indicam que são mais participativos os que possuem maior escolaridade, os membros das classes médias, os homens, os casados, os que fazem parte das maiorias étnicas, ou seja, aqueles que ocupam uma posição de centralidade da estrutura social. Verba e Nie (1972), por meio de pesquisas empíricas comparadas, chegaram a conclusões semelhantes ao identificaram uma correspondência entre status social e participação. A participação política, portanto, seria facilitada para aqueles que possuem quantidades maiores de recursos materiais e simbólicos (Avelar, 2004).

O pressuposto que está por trás do argumento da centralidade é que "normalmente, maior status social implica mais recursos materiais (mas também de tempo livre) para investir na participação política, mas também uma maior probabilidade de ser bem sucedido (através das relações pessoais com indivíduos poderosos) e, especialmente, um maior sentimento de realização pessoal" (Della Porta, 2008).

Incorporando dimensões que vão para além dos limites das variáveis sócio-demográficas, destacamos também o modelo explicativo do voluntarismo cívico proposto por Verba, Schlozman e Brady (1995). Para esses autores fatores de ordem política e individual, como tempo e habilidades cívicas, desempenhariam papel significativo na propensão dos indivíduos a participar. Dessa forma, a engajamento político seria resultado do somatório de recursos objetivos e subjetivos, que são distribuídos de forma desigual nas sociedades democráticas.

Igualmente importantes são as proposições oriundas de uma "sociologia da participação", que tem defendido a relevância das chamadas redes de interação (Avritzer, 1997). As origens de tal reflexão podem ser encontradas nos trabalhos de Pizzorno $(1975,1985)$ sobre a relação entre identidades, interesses, e participação política. Tal literatura, que recorre aos argumentos das redes e das identidades, ganhou reforço com os estudos sobre os "novos movimentos sociais" (Touraine, 1994), "sociedade civil" (Cohen \& Arato, 1992), e, mais recentemente, com a difusão das teses de Putnam sobre o "capital social" (Putnam, 1996; 2002). Ainda que existam diferenças substanciais entre essas teorias, elas concordam na afirmação da importância dessas 
redes de interação social na composição das diferentes identidades que podem ser promotoras da participação política do cidadão.

Não podemos deixar de mencionar também a corrente que, inspirada na teoria da escoIha racional, propõe que a participação deve ser analisada em termos do cálculo racional dos atores, sobretudo quando estão envolvidos processos de distribuição de bens públicos. Olson (1999), por exemplo, recorre ao argumento dos benefícios seletivos e da coerção para afirmar que a condição de participação seria a obtenção de benefícios que seriam apropriados privadamente pelos participantes do processo ou mediante o risco de coerção pelo não engajamento.

A abordagem institucionalista também merece ser mencionada. Ainda que a sua diversidade interna seja considerável, a tese fundamental dessa perspectiva afirma que os interesses e preferências dos atores políticos são constrangidos por mecanismos e sistemas institucionais que podem ou não gerar estruturas de oportunidades para a ação política dos grupos sociais (Rennó, 2003). Portanto, as instituições geram incentivos, oportunidades e restrições, impactando a organização e o comportamento político-social. Norris (2007), em recente revisão da literatura sobre o engajamento político, destaca a importância dos diferentes desenhos institucionais nos níveis de participação eleitoral.

Por fim, gostaríamos de abordar a perspectiva que deriva dos estudos sobre mudança cultural inaugurados há mais de três décadas por Ronald Inglehart. O ponto de partida dessa abordagem é a afirmação de uma reorientação valorativa que estaria ocorrendo principalmente em razão do desenvolvimento econômico experimentado a partir da segunda metade do século XX, especialmente pelas sociedades industriais avançadas (Inglehart, 1977; 1990; 2001; Inglehart \& Welzel, 2005; Ribeiro, 2007).

No campo político essa mudança estaria relacionada aos processos de democratização, pois conduziria à adoção de valores e atitudes congruentes com essa forma de governo (Inglehart \& Welzel, 2005). Ainda que pareça paradoxal à primeira vista, tais orientações subjetivas também seriam acompanhadas de uma postura crítica em relação ao funcionamento das instituições políticas e, sobretudo, pelo questionamento dos mecanismos tradicionais de representação (Inglehart, 1990; 2001; Inglehart \& Welzel, 2005). O reflexo dessa atitude crítica seria a redução significativa nas taxas de mobilização política convencional verificada nas últimas décadas nas sociedades avançadas industrialmente. A contradição, todavia, seria apenas aparente. Esse quadro não seria um sinal de apatia por parte dos públicos dessas nações, pois em paralelo à redução na participação tradicional estaria ocorrendo processo inverso nas chamadas elite-directed political action, ou seja, nas atividades de contestação às instituições e elites estabelecidas (Norris, 2007; Inglehart \& Welzel, 2005).

Uma vez superados os limites estritos da sobrevivência física e econômica, os indivíduos estariam se preocupando cada vez mais com questões relacionadas à sua auto-expressão, gerando uma "intervenção cidadã na política" (Inglehart, 2001, p. 221). O desejo de tomar parte nos assuntos públicos de uma maneira mais ativa e direta estaria acompanhando, portanto, a mudança pós-materialista. Evidências empíricas robustas têm sido apresentadas desde o final da década de 1970 para confirmar esses argumentos (Barnes et al., 1979; Inglehart, 1999; Norris, 2007). Em perspectiva mundial, os valores pós-materialistas estariam fortemente associados a ações políticas não-convencionais, como manifestações, boicotes, ocupações, bem como ao interesse por política em geral.

Ainda que nossa pretensão não seja questionar ou validar as abordagens sumariamente elencadas acima, construímos nossa proposta de investigação que se concentra sobre outro conjunto de fatores: as experiências políticas dos indivíduos no seu processo de socialização 
política. É preciso reconhecer que, indiretamente, essa dimensão do fenômeno está presente nas abordagens do voluntarismo cívico, da sociologia do ativismo, do institucionalismo e da mudança cultural pós-materialista, todavia, também é verdade que em nenhuma delas a questão das diferentes experiências políticas dos distintos grupos geracionais ocupa o centro da argumentação.

Nosso ponto de partida para a sustentação desse argumento está nas clássicas teorias sobre o processo de formação dos padrões de atitudes e comportamentos dos indivíduos em relação aos objetos políticos. Questionando afirmações de natureza psicológica de que a formação deste padrão se daria apenas nos primeiros anos da vida, autores como Almond e Verba defendem que experiências na chamada fase pré-adulta e também na maturidade têm importância fundamental para a configuração das orientações políticas subjetivas. Isso não quer dizer que as experiências da primeira infância não tenham relevância, mas sim que

[...] early socialization experiences significantly affect an individual's basic personality predispositions and may therefore affect his political behavior, but numerous other factors intervene between these earliest experiences and later political behavior that greatly inhibit the impact of the former on the latter (Almond \& Verba, 1989, p. 266-7).

Começando na infância, mas se estendendo por todas as demais fases da vida do indivíduo, devemos definir o processo de socialização política como "[...] o conjunto de experiências que, no processo de formação da identidade social do indivíduo, tem influência na cristalização do seu papel como ator significativo ou não no sistema político e as crenças que ele desenvolve em relação à política e as instituições [...]" (Baquero, 1997). Sendo assim, dá-se continuamente, na medida em que as pessoas vivenciam suas experiências sociais em espaços distintos como a família e a escola, os seus padrões de atitudes e procedimentos vão sendo formados e/ou alterados (Almond \& Powell, 1972).

Desta forma, as experiências que ocorrem em instituições voltadas aos adultos ou préadultos, como sindicatos, clubes sociais e esportivos, ambientes de trabalho, dentre outros, são de fundamental importância para a formação da cultura política. Isso, entretanto, não nos impede de apontar que as experiências de socialização que ocorrem na infância e juventude são as que mais impactam as crenças, valores e atitudes políticos dos indivíduos (Rokeach, 1968).

Acerca desta questão, as contribuições de Robert Dahl (1997) são de grande valia, pois afirmam a importância da socialização precoce diante dos demais momentos e experiências políticas. Para esse autor, as orientações acerca dos objetos políticos são adquiridas nas primeiras duas décadas de vida de uma pessoa, período em que se é mais receptivo a elas. Quando se ultrapassa esse período, os indivíduos tendem a possuir uma visão mais cristalizada e suas crenças tendem a se tornar mais estáveis e menos suscetíveis a mudanças (Ibid., p. 160).

Desta forma, além dos fatores relacionados à centralidade social, aos recursos objetivos e subjetivos, às redes de interações, aos cálculos racionais dos atores, aos diferentes arranjos institucionais e à mudança valorativa, também merecem ser consideradas na explicação da participação política o que podemos chamar de conjunto de experiências de socialização política por que passam os atores sociais.

A consideração dessa dimensão, consequentemente, nos remete ao tema das diferenças geracionais, uma vez que indivíduos nascidos em diferentes momentos históricos provavelmente tenham passado por situações e acontecimentos distintos com impactos consideráveis 
sobre as disposições políticas e os potenciais efeitos quanto as suas chances de envolvimento político.

O caso brasileiro, em razão da sua relativamente recente democratização, oferece uma ótima oportunidade para testar a pertinência dessa afirmação, pois atualmente teríamos grupos geracionais que experimentaram, nas suas fases de socialização (principalmente infantil e préadulta), diferentes situações e acontecimentos sob a vigência de modelos institucionais distintos.

O processo de democratização brasileiro, amplamente discutido por inúmeros cientistas sociais, é repleto de peculiaridades que o tornam singular ${ }^{3}$. Lenta e gradual, a transição levou 11 anos para restabelecer os direitos civis e mais cinco para que os cidadãos pudessem eleger seu candidato à presidência. Podemos identificar pelo menos três fases distintas nesse longo caminho: a primeira, que vai de 1974 a 1982, dominada totalmente pelos militares, e com poucos avanços; a segunda, que vai de 1982 a 1985, também dominada pelos militares, mas com a incorporação de outros atores políticos que passam a desempenhar um importante papel; e, por fim, a fase que vai de 1985 a 1989, quando os militares deixam de desempenhar o papel principal, os civis assumem suas funções e setores da sociedade civil organizada passam a participar do processo político (Kinzo, 2001, p. 4-5).

A partir desta periodização, podemos contabilizar pouco mais de duas décadas de democratização em curso e/ou vigência de instituições democráticas em nosso país. Ainda que seja um período muito curto para uma análise conclusiva envolvendo o tema da mudança de valores, atitudes e comportamentos políticos, devemos reconhecer que já temos ao menos uma nova geração socializada sob a influência das instituições fundamentais de uma democracia liberal. Partidos, parlamentos, eleições, direitos civis e políticos fazem parte da história de vida dos atuais adolescentes e jovens desde suas primeiras experiências de socialização política.

Podemos concluir, portanto, que indivíduos brasileiros de faixas etárias distintas tiveram diferentes experiências de socialização política em decorrência da recente mudança institucional operada no país. Indivíduos que, atualmente, possuem de 15 a 25 anos viveram sob instituições democráticas desde seus nascimentos, ao passo que aqueles agrupados em faixas etárias mais elevadas passaram parte importante do seu período de maior suscetibilidade sob o domínio de um desenho institucional autoritário ou em transição.

Não podemos deixar de considerar a hipótese de que esses últimos indivíduos, membros de gerações mais velhas, ao terem vivenciado as duas formas de governo, possam também ter suas orientações subjetivas alteradas positivamente pela democratização, passando a manifestar valores, atitudes e comportamentos mais participativos. Esse raciocínio, entretanto, não invalida o pressuposto aqui adotado de que, após as duas primeiras décadas de socialização, os valores e crenças tendem a estar mais consolidados e as suas mudanças tendem a ser mais sutis (Rokeach, 1968).

Sendo assim, ainda que as mudanças ocorram em todos os grupos geracionais, é plausível supor que o efeito verificado nos mais jovens seja maior do que o encontrado nas demais. Em outras palavras, tomando como verdadeira a afirmação de que instituições democráticas favorecem o desenvolvimento de disposições, atitudes e comportamentos mais ativos nos cidadãos que vivem sob sua influência, poderíamos supor a existência de diferenciais significativos em indicadores de participação entre diferentes grupos etários.

\section{QUESTÕES METODOLÓGICAS}

Para testar empiricamente a validade das hipóteses indicadas acima, utilizamos dados produzidos pela última pesquisa conduzida no Brasil pelo projeto World Values Surveys (WVS ${ }^{4}$, concluída em 2006. O WVS é uma grande investigação sobre mudanças socioculturais e políticas, executada por uma rede global de cientistas sociais a partir de surveys aplicados a amostras nacionais representativas de mais de 80 nações espalhadas por todos os continentes. As coletas

3 Dentre várias outras análises sobre a transição, ver Martins (1986), Stepan (1989) e Diniz (1985).

Século XXI, UFSM, Santa Maria, v. 1, n. 2, p. 62-78, jul./dez. 2011 
de dados têm se repetido desde o início da década de 1980 em sucessivas ondas (1980-1984, 1990-1993, 1995-1997, 1999-2002 e 2005-2008) e, na sua última edição concluída, produziu dados representativos para mais de $80 \%$ da população mundial ${ }^{5}$.

Os procedimentos de análise aqui empregados consistem basicamente na realização de cruzamentos e testes de associação para identificar a natureza do relacionamento entre as idades dos entrevistados, recodificada para representar distintos grupos geracionais, e indicadores de diferentes modalidades de participação política. Como essas variáveis possuem nível de mensuração ordinal, utilizamos o coeficiente Gamma em todos os testes binários (BOHRNSTEDT \& KNOKE, 1982).

Antes de passarmos à análise propriamente dita, consideramos que seja interessante apresentar uma tabela em que as diferentes idades dos entrevistados apareçam agrupadas com seus respectivos períodos de maior receptividade para a formação de seus valores, atitudes e padrões de comportamento político (Tabela 1).

Podemos identificar que os três primeiros grupos foram os que tiveram a maior parte dos seus respectivos períodos de receptividade sob a vigência das instituições democráticas ou durante o processo de transição para as mesmas. Apesar dos períodos em questão serem evidentemente curtos demais para a verificação de mudanças nos valores de uma população, como propomos uma análise no nível individual o enfoque sobre as duas primeiras décadas de receptividade nos parece adequado. Trata-se, portanto, de verificar se a experiência individual de viver esse período de socialização sob a influência de um processo de democratização ou de instituições democráticas instaladas produziu algum impacto sobre as disposições participativas dos entrevistados.

TABELA 1 - GRUPOS ETÁRIOS E PERÍODOS DE MAIOR RECEPTIVIDADE

\begin{tabular}{lll}
\hline $\begin{array}{l}\text { GRUPOS ETÁRIOS EM } \\
2006\end{array}$ & $\begin{array}{l}\text { PERÍODOS DE MAIOR } \\
\text { RECEPTIVIDADE* }\end{array}$ \\
\hline 15 a 20 & 15 & $\begin{array}{l}1991 \text { a } 2006 \\
1986 \text { a } 2006\end{array}$ \\
\hline 21 a 25 & 21 & 1985 a 2005 \\
& 25 & 1981 a 2001 \\
\hline 26 a 30 & 26 & 1980 a 2000 \\
& 30 & 1976 a 1996 \\
\hline 31 a 35 & 31 & 1975 a 1995 \\
& 35 & 1971 a 1991 \\
\hline 36 a 40 & 36 & 1970 a 1990 \\
& 40 & 1966 a 1986 \\
\hline 41 a 45 & 41 & 1965 a 1985 \\
\hline 46 a 50 & 45 & 1961 a 1981 \\
\hline
\end{tabular}

Notas: *O período de maior receptividade vai do nascimento aos 20 anos, ou seja, as duas primeiras décadas de vida dos indivíduos.

Fonte: Elaboração dos autores.

\footnotetext{
4 Essa base está disponível no endereço http://www.worldvaluessurvey.org/. Aproveitamos a oportunidade para agradecer a Ronald Inglehart, presidente do WVS, por permitir o acesso aos dados.

${ }^{5}$ No Brasil, a Universidade de Brasília foi responsável pela aplicação dos questionários a uma amostra de 1500 pessoas entre os dias 01/11 e 26/12/2006. Informações técnicas adicionais sobre os procedimentos amostrais podem ser obtidas no site mencionado na nota anterior.
} 


\section{PARTICIPAÇÃO E GRUPOS GERACIONAIS}

Para a apresentação dos resultados, iniciamos com alguns indicadores relativos às modalidades que definimos anteriormente como convencionais ou tradicionais. Isso é possível porque o WVS disponibiliza um conjunto de dados relativos à atuação voluntária dos entrevistados em diferentes instituições, organizações ou atividades. Essas informações são geradas através de questões que levam os indivíduos a escolherem, em relação a um leque de organizações ou atividades, a alternativa que melhor define sua situação: não participa, é membro inativo ou é membro ativo.

As tabelas que seguem apresentam os cruzamentos entre algumas dessas variáveis e os diferentes grupos geracionais dispostos na Tabela 1. Dentre as organizações envolvidas nas perguntas, selecionamos aquelas que desempenham papel político mais relevante nos regimes democráticos contemporâneos.

Antes de apresentarmos os dados sobre as associações, seria interessante analisarmos em cada caso os níveis atuais de atividade do público brasileiro e também como tem sido sua evolução ao longo do período coberto pelas pesquisas do WVS.

A Tabela 2, com dados referentes à pesquisa de 2006, mostra um quadro de baixa participação. No que diz respeito aos sindicatos, se somarmos os percentuais de membros ativos e inativos encontramos apenas $18,9 \%$ de participantes. Consulta aos dados anteriores revela inclusive uma ligeira queda, pois em 1997 contávamos com 9,7\% de membros ativos. A participação em partidos políticos é igualmente pequena uma vez que na pesquisa de 2006 apenas 5,3\% se declararam membros ativos. Aqui novamente constatamos uma redução em relação aos dados de 1997, quando $7,2 \%$ dos entrevistados se definiram como membros ativos dessas instituições políticas fundamentais para a democracia. Por fim, no que diz respeito às associações profissionais, os números também não são muito expressivos ( $8,7 \%$ de ativos) e podemos identificar tendência de redução entre as duas pesquisas

TABELA 2. PARTICIPAÇÃO CONVENCIONAL NO BRASIL, 2006. (\%)

\begin{tabular}{llll}
\hline & Não Participa & $\begin{array}{l}\text { Participa como } \\
\text { membro inativo }\end{array}$ & $\begin{array}{l}\text { Participa } \\
\text { ativamente }\end{array}$ \\
\hline Sindicatos & 81,1 & 10,2 & 8,7 \\
Partidos Políticos & 89,8 & 5,0 & 5,3 \\
Associações Profissionais & 85,8 & 5,5 & 8,7 \\
\hline
\end{tabular}

Fonte: WORLD VALUES SURVEY 2005 OFFICIAL DATA FILE v.20081015, 2008. World Values Survey Association.

Passando à análise da relação entre participação nessas organizações/atividades e os diferentes grupos etários, a Tabela 3 apresenta o cruzamento e o resultado do teste de associação entre a variável relativa aos grupos geracionais e a participação em sindicatos. Podemos constatar que o teste atingiu nível de significância bastante exigente $(0.000)$ e seu valor foi positivo, ainda que fraco (0.20). Esses resultados indicam que existe sim uma associação entre a participação nessas organizações de trabalhadores e que, na medida em que avança a idade, aumenta também a participação. A simples inspeção visual das colunas da tabela já indica isso, pois os percentuais dos que não participam vão decrescendo na medida em que avançamos em direção aos grupos etários mais velhos. 
TABELA 3. PARTICIPAÇÃO EM SINDICATOS E GRUPOS ETÁRIOS, BRASIL, 2006.

\begin{tabular}{lccc}
\hline \multirow{4}{*}{ GRUPOS ETÁRIOS } & \multicolumn{3}{l}{ PARTICIPAÇÃO EM SIN DICATOS } \\
\cline { 2 - 4 } & $\begin{array}{l}\text { Não } \\
\text { Participa }\end{array}$ & $\begin{array}{l}\text { Participa como } \\
\text { membro inativo }\end{array}$ & $\begin{array}{l}\text { Participa } \\
\text { ativamente }\end{array}$ \\
\hline 15 a 20 & $93.8 \%$ & $4.7 \%$ & $1.6 \%$ \\
21 a 25 & $85.9 \%$ & $7.5 \%$ & $6.5 \%$ \\
26 a 30 & $81.4 \%$ & $9.9 \%$ & $8.7 \%$ \\
31 a 35 & $81.8 \%$ & $9.4 \%$ & $8.8 \%$ \\
36 a 40 & $81.9 \%$ & $11.9 \%$ & $6.3 \%$ \\
41 a 45 & $83.3 \%$ & $8.7 \%$ & $8.0 \%$ \\
46 a 50 & $70.8 \%$ & $13.8 \%$ & $15.4 \%$ \\
+ de 50 & $76.2 \%$ & $12.5 \%$ & $11.2 \%$ \\
\hline$y=.20 \quad p=.000$ & \multicolumn{3}{c}{} \\
\hline
\end{tabular}

Fonte: WORLD VALUES SURVEY 2005 OFFICIAL DATA FILE v.20081015, 2008. World Values Survey Association.

A experiência de viver sob a vigência de instituições democráticas, que garantem constitucionalmente dentre outras coisas o direito de representação sindical, não tem produzido entre os mais jovens uma disposição mais participativa nessa modalidade. Aqueles que apenas parcialmente tiveram suas experiências de socialização infantil e pré-adulta sob a democracia manifestaram envolvimento maior.

Esses resultados nos levam a considerar a hipótese de que esse diferencial possa ser explicado pelas experiências negativas desses estratos de mais idade nos seus períodos de formação. Sobretudo aqueles que vivenciaram o regime de exceção que vigorou em nosso país podem ter desenvolvido disposições subjetivas que valorizam aquilo que thes era negado no passado.

Considerando os pressupostos dos estudos sobre mudança cultural, os resultados que encontramos não geram surpresa, pois, como afirma Inglehart e Welzel (2005), as novas gerações que mais fortemente experimentam o processo de alteração nas prioridades valorativas tendem a se afastar dessas modalidades tradicionais ao mesmo tempo em que tendem a se engajarem em formas não convencionais. Nesse sentido, as experiências democráticas desses grupos etários mais jovens produziriam efeito negativo sobre o ativismo tradicional e positivo sobre o contestatório.

Essa hipótese parece se confirmar quando consideramos a participação em partidos (Tabela 4), pois o teste de associação se mostrou estatisticamente significativo (0.037) com valor positivo, ainda que reduzido $(0,13)$. Assim como apontamos anteriormente, a leitura das colunas já revela uma disposição mais participativa entre os grupos de maior idade. No que diz respeito à participação nessas organizações políticas tradicionais, a associação existe e indica que mais jovens manifestam perfil menos engajado. 
TABELA 4. PARTICIPAÇÃO EM PARTIDOS POLÍTICOS E GRUPOS ETÁRIOS, BRASIL, 2006.

\begin{tabular}{|c|c|c|c|}
\hline \multirow[b]{2}{*}{ GRUPOS ETÁRIOS } & \multicolumn{3}{|c|}{ PARTICIPAÇÃO EM PARTIDOS } \\
\hline & $\begin{array}{l}\text { Não } \\
\text { Participa }\end{array}$ & $\begin{array}{l}\text { Participa como } \\
\text { membro inativo }\end{array}$ & $\begin{array}{l}\text { Participa } \\
\text { ativamente }\end{array}$ \\
\hline 15 a 20 & $93.0 \%$ & $4.7 \%$ & $2.3 \%$ \\
\hline 21 a 25 & $90.5 \%$ & $5.0 \%$ & $4.5 \%$ \\
\hline 26 a 30 & $93.8 \%$ & $1.9 \%$ & $4.3 \%$ \\
\hline 31 a 35 & $90.6 \%$ & $2.8 \%$ & $6.6 \%$ \\
\hline 36 a 40 & $86.9 \%$ & $8.1 \%$ & $5.0 \%$ \\
\hline 41 a 45 & $90.6 \%$ & $2.2 \%$ & $7.2 \%$ \\
\hline 46 a 50 & $85.5 \%$ & $5.3 \%$ & $9.2 \%$ \\
\hline+ de 50 & $88.5 \%$ & $7.1 \%$ & $4.5 \%$ \\
\hline$y=.13 \quad p=.037$ & & & \\
\hline
\end{tabular}

Fonte: WORLD VALUES SURVEY 2005 OFFICIAL DATA FILE v.20081015, 2008. World Values Survey Association.

Dentre as modalidades tradicionais aqui consideradas, apenas em relação às associações profissionais não encontramos associação válida. Como a Tabela 5 mostra, o teste de significância retornou valores superiores aos 0,05 exigidos, indicando assim que não existe associação entre a variável que distingue os grupos etários e a que mede a participação nesse terceiro tipo de organização, ou seja, níveis semelhantes de envolvimento e afastamento podem ser encontrados em todos os estratos de idade, não sendo essa variável um fator relevante de explicação. A partir de nossa linha de argumentação, podemos entender que as distintas experiências por que passaram tais grupos ou estratos não produziram impactos significativos sobre suas disposições em relação a essas organizações.

TABELA 5. PARTICIPAÇÃO EM ASSOCIAÇÕES PROFISSIONAIS E GRUPOS ETÁRIOS, BRASIL, 2006.

\begin{tabular}{|c|c|c|c|}
\hline \multirow[b]{2}{*}{ GRUPOS ETÁRIOS } & \multicolumn{3}{|c|}{ PARTICIPAÇÃO EM ASSOC. PROFISSIONAIS } \\
\hline & $\begin{array}{l}\text { Não } \\
\text { Participa }\end{array}$ & $\begin{array}{l}\text { Participa como } \\
\text { membro inativo }\end{array}$ & $\begin{array}{l}\text { Participa } \\
\text { ativamente }\end{array}$ \\
\hline 15 a 20 & $93.0 \%$ & $3.9 \%$ & $3.1 \%$ \\
\hline 21 a 25 & $84.4 \%$ & $4.5 \%$ & $11.1 \%$ \\
\hline 26 a 30 & $88.8 \%$ & $3.8 \%$ & $7.5 \%$ \\
\hline 31 a 35 & $87.2 \%$ & $2.8 \%$ & $10.0 \%$ \\
\hline 36 a 40 & $84.3 \%$ & $4.4 \%$ & $11.3 \%$ \\
\hline 41 a 45 & $86.3 \%$ & $6.5 \%$ & $7.2 \%$ \\
\hline 46 a 50 & $76.7 \%$ & $10.1 \%$ & $13.2 \%$ \\
\hline+ de 50 & $85.8 \%$ & $7.1 \%$ & $7.1 \%$ \\
\hline$y=-.08 \quad p=.083$ & & & \\
\hline
\end{tabular}

Fonte: WORLD VALUES SURVEY 2005 OFFICIAL DATA FILE v.20081015, 2008. World Values Survey Association. 
Os resultados até agora apresentados dizem respeito ao que definimos como participação política convencional e relevam que, no que tange às duas instituições mais relevantes, existem indícios de maior envolvimento naqueles grupos com maior idade. Vale lembrar que pressupomos que os membros desses grupos tiveram a maior parte das suas experiências de socialização política sob a vigência da democracia. Como mencionamos anteriormente, esses achados não se opõem frontalmente às nossas expectativas iniciais, pois a literatura recente tem apontado que a mudança geracional está mais relacionada com outras modalidades de ativismo político. Para tentar identificar a consistência dessa argumentação, a seguir nos voltamos para essas formas alternativas de ação.

$O$ interesse por essas formas tem como ponto de referência importante o estudo que culminou na publicação da obra Political Action (Barnes et al., 1979), cujo objetivo foi verificar se as mudanças culturais inter-geracionais e a elevação nos níveis de qualificação estavam impulsionando o surgimento de cidadãos mais ativos no cenário norte-americano da segunda metade do século $X X$.

Dando continuidade a essas investigações, Inglehart (2001) comparou décadas depois dados de 21 países e concluiu que tanto em termos de ação efetiva, quanto nas disposições para tal ocorreu uma tendência de ampliação na adesão a essas práticas em escala mundial (Ibid.). Vejamos se essa mesma tendência se manifesta no contexto brasileiro.

Assim como procedemos anteriormente, primeiramente apresentamos os resultados atuais e a sua evolução no período coberto pelas pesquisas do WVS. Começando pela participação por meio da assinatura de abaixo-assinados ou petições (Tabela 6), verificamos um quadro relativamente positivo, sobretudo se comparado com os níveis de envolvimento em organizações tradicionais estudados anteriormente. $O$ público brasileiro parece mais propenso a esse tipo de ação, com mais da metade da amostra afirmando ter participado. Ao adicionarmos o percentual daqueles que escolheram a opção "poderia participar", temos mais de $83 \%$ de ocorrência. A comparação desses dados com os recolhidos na pesquisa anterior do WVS indica certa tendência de ampliação nos percentuais, pois em 1997 esse percentual atingiu 47,1 pontos.

TABELA 6. PARTICIPAÇÃO NÃO CONVENCIONAL NO BRASIL, 2006. (\%)

\begin{tabular}{llll} 
& & Poderia & Tem \\
ATIVIDADES & Nunca participaria & participar & participado \\
\hline Abaixo-assinados & 16,9 & 27,6 & 55,5 \\
Boicotes & 66,8 & 25,3 & 7,8 \\
Passeatas/manifestações & 41,9 & 39,8 & 18,2 \\
\hline
\end{tabular}
Association.

Fonte: WORLD VALUES SURVEY 2005 OFFICIAL DATA FILE v.20081015, 2008. World Values Survey

No que diz respeito à participação em boicotes, entretanto, a situação é menos positiva. Na realidade isso já era algo esperado, pois a assinatura de abaixo-assinados ou petições é uma ação que depende quase que exclusivamente da intenção individual, além de não envolver grandes volumes de recursos escassos, como tempo e dinheiro. Boicotes, passeatas e manifestações dependem de uma considerável organização e a participação exige algum investimento por parte dos cidadãos. Essas diferenças se refletem nos percentuais, uma vez que encontramos entre os brasileiros apenas $7,8 \%$ de envolvimento nessa segunda modalidade contestatória. Podemos, inclusive, identificar uma redução em relação aos dados de 1991 (10,3\%). 
Os dados sobre participação em passeatas ou manifestações pacíficas são relativamente mais positivos, ainda que não possam ser comparados com aqueles relacionados à assinatura de abaixo-assinados. Neste item verificamos $18,2 \%$ de envolvimento e, se somarmos as respostas daqueles que "poderiam participar", temos mais de 50\%. Entretanto, aqui também podemos identificar certa tendência de redução no contingente de participantes. Em 1997, 24,8\% dos entrevistados brasileiros optaram pela opção "tem participado", ou seja, mais de seis pontos acima do que a última pesquisa registrou.

Passando às associações, a Tabela 7 traz o cruzamento envolvendo os grupos etários e a participação na primeira modalidade não convencional. Primeiramente, é preciso alertar para o fato de que o teste não se mostrou estatisticamente significativo $(0,081)$, indicando assim que as variáveis não estão relacionadas da forma como esperávamos. Esse resultado revela que os grupos considerados em nossa análise não se distinguem em termos do ativismo nessa forma específica. Esse dado conduz à conclusão de que as diferentes experiências de socialização política por que passaram os membros desses grupos não produziram efeitos relevantes sobre suas disposições em relação a essa forma de atuação.

TABELA 7. PARTICIPAÇÃO EM ABAIXO-ASSINADOS E GRUPOS ETÁRIOS, BRASIL, 2006.

\begin{tabular}{lccc}
\hline \multirow{2}{*}{ GRUPOS ETÁRIOS } & \multicolumn{3}{c}{ PARTICIPAÇÃO EM ABAIXO -ASSINADOS } \\
\cline { 2 - 4 } & Nunca participa & Participaria & $\begin{array}{l}\text { Sempre } \\
\text { participa }\end{array}$ \\
\hline 15 a 20 & $14.4 \%$ & $31.1 \%$ & $54.5 \%$ \\
21 a 25 & $17.3 \%$ & $31.7 \%$ & $51.0 \%$ \\
26 a 30 & $13.0 \%$ & $30.4 \%$ & $56.5 \%$ \\
31 a 35 & $14.4 \%$ & $21.5 \%$ & $64.1 \%$ \\
36 a 40 & $11.7 \%$ & $27.2 \%$ & $61.1 \%$ \\
41 a 45 & $15.2 \%$ & $26.1 \%$ & $58.7 \%$ \\
46 a 50 & $15.7 \%$ & $25.4 \%$ & $59.0 \%$ \\
+ de 50 & $23.5 \%$ & $27.4 \%$ & $49.1 \%$ \\
\hline$y=-.05$ & $p=.081$ & \multicolumn{3}{c}{} \\
\hline
\end{tabular}
Association.

Fonte: WORLD VALUES SURVEY 2005 OFFICIAL DATA FILE v.20081015, 2008. World Values Survey

O mesmo ocorre quando consideramos o envolvimento dos entrevistados em boicotes, pois o teste de significância estatística também retornou valor superior $(0,836)$ ao exigido $(0,05)$ (Tabela 8). Desta forma, ganha consistência a afirmação de que o fato de viverem sob diferentes arranjos institucionais não produz efeitos relevantes sob as disposições participativas dos grupos aqui considerados. Os efeitos da chamada mudança geracional, portanto, não parecem se confirmar quanto ao maior envolvimento nessas atividades de protesto. 
TABELA 8. PARTICIPAÇÃO EM BOICOTES E GRUPOS ETÁRIOS, BRASIL, 2006.

\begin{tabular}{|c|c|c|c|}
\hline \multirow[b]{2}{*}{ GRUPOS ETÁRIOS } & \multicolumn{3}{|c|}{ PARTICIPAÇÃO EM BOICOTES } \\
\hline & Nunca participa & Participaria & $\begin{array}{l}\text { Sempre } \\
\text { participa }\end{array}$ \\
\hline 15 a 20 & $58.3 \%$ & $34.6 \%$ & $7.1 \%$ \\
\hline 21 a 25 & $65.8 \%$ & $28.1 \%$ & $6.1 \%$ \\
\hline 26 a 30 & $73.4 \%$ & $18.8 \%$ & $7.8 \%$ \\
\hline 31 a 35 & $73.3 \%$ & $18.2 \%$ & $8.5 \%$ \\
\hline 36 a 40 & $66.9 \%$ & $24.4 \%$ & $8.8 \%$ \\
\hline 41 a 45 & $66.2 \%$ & $24.3 \%$ & $9.6 \%$ \\
\hline 46 a 50 & $56.1 \%$ & $34.1 \%$ & $9.8 \%$ \\
\hline+ de 50 & $68.4 \%$ & $24.6 \%$ & $7.0 \%$ \\
\hline$y=-.01 \quad p=.836$ & & & \\
\hline
\end{tabular}
Association.

Fonte: WORLD VALUES SURVEY 2005 OFFICIAL DATA FILE v.20081015, 2008. World Values Survey

A exceção fica por conta do envolvimento em passeatas ou manifestações (Tabela 9). 0 cruzamento com a variável relativa aos grupos etários apontou a existência de associação estatisticamente significativa $(p=0.028)$ e no sentido negativo, ainda que bastante fraco $(-0.06)$. Ao considerarmos apenas a questão da significância e o sinal do coeficiente Gamma, podemos concluir que a hipótese do efeito positivo da mudança geracional e das experiências potencialmente diferentes desses grupos mais jovens é válida. Isso porque o resultado indica que a elevação na escala dos grupos é acompanhada de reduções de envolvimento nessas formas de protesto, ou seja, os mais jovens seriam mais ativos. Não obstante, ainda que defensável essa conclusão, ela deve ser relativizada em razão da baixa intensidade desse relacionamento e levando em consideração os resultados obtidos nos cruzamentos anteriores.

TABELA 9. PARTICIPAÇÃO EM PASSEATAS/MANIFESTAÇÕES GRUPOS ETÁRIOS, BRASIL, 2006.

\begin{tabular}{|c|c|c|c|}
\hline \multirow[b]{2}{*}{ GRUPOS ETÁRIOS } & \multicolumn{3}{|c|}{ PARTICIPAÇÃO EM PASSEATAS/MANIFESTAÇÕES } \\
\hline & Nunca participa & Participaria & $\begin{array}{l}\text { Sempre } \\
\text { participa }\end{array}$ \\
\hline 15 a 20 & $40.5 \%$ & $46.6 \%$ & $13.0 \%$ \\
\hline 21 a 25 & $36.5 \%$ & $46.0 \%$ & $17.5 \%$ \\
\hline 26 a 30 & $39.8 \%$ & $36.6 \%$ & $23.6 \%$ \\
\hline 31 a 35 & $38.9 \%$ & $41.1 \%$ & $20.0 \%$ \\
\hline 36 a 40 & $37.9 \%$ & $44.1 \%$ & $18.0 \%$ \\
\hline 41 a 45 & $44.1 \%$ & $42.6 \%$ & $13.2 \%$ \\
\hline 46 a 50 & $36.6 \%$ & $41.0 \%$ & $22.4 \%$ \\
\hline+ de 50 & $50.3 \%$ & $31.9 \%$ & $17.8 \%$ \\
\hline$y=-.06 \quad p=.028$ & & & \\
\hline
\end{tabular}
Association.

Fonte: WORLD VALUES SURVEY 2005 OFFICIAL DATA FILE v.20081015, 2008. World Values Survey 


\section{CONSIDERAÇÕES FINAIS}

Em termos gerais, os dados apresentados nesse artigo colocam em xeque os efeitos positivos da mudança geracional sobre o desenvolvimento de uma postura mais ativa ou participativa no cenário nacional. Considerando nosso recente processo de transição democrática, seria plausível supor que os estratos populacionais mais jovens que viveram seus períodos mais suscetíveis de socialização sob a vigência de instituições em alguma medida fomentadoras do envolvimento político, manifestassem uma disposição mais engajada. $\mathrm{O}$ cenário que identificamos, todavia, não confirma essa suposição.

Em termos mais específicos é possível afirmar que:

1) No que tange às formas convencionais de participação, os mais jovens, na comparação com os mais velhos, são menos envolvidos. Essa afirmação vale para as duas principais instituições aqui analisadas: sindicatos e partidos. $O$ fato de terem sido socializados sob a existência de tais organizações políticas não conduziu a maior envolvimento. Inversamente, podemos aventar a possibilidade de que as experiências negativas dos estratos com mais idade com o regime autoritário possam explicar a maior participação. Esses resultados, todavia, não seriam essencialmente negativos caso as gerações mais jovens se manifestassem de forma mais ativa em outras modalidades.

2) Nas modalidades de protesto ou não convencionais de forma diferente, porém conduzindo a conclusões semelhantes, os testes indicaram na maioria dos casos a inexistência de relacionamento significativo. Estratos com menos e mais idade não se diferenciam em termos desse ativismo contestatório, refutando a hipótese de que a mudança geracional estaria favorecendo o surgimento de uma cidadania mais crítica e também a de que a vivência em contextos institucionais democráticos poderia favorecer a emergência de posturas ativistas por meio dos processos de socialização política.

Tais resultados não subsidiam refutações contundentes sobre o problema da relação causal entre valores/atitudes/comportamentos e instituições para o caso brasileiro. Tal pretensão necessitaria de um maior período de vigência democrática em nosso país e também de séries de dados mais longas. Nesse trabalho nos limitamos a apresentar indicações de que existe uma juventude nascida ou socializada sob a existência de instituições democráticas e que não demonstra possuir disposições participativas diferentes de outros estratos da população que tiveram outras experiências de socialização.

\section{REFERÊNCIAS BIBLIOGRÁFICAS}

ALMOND, G. \& POWELL JR, B. 1972. Uma teoria da política comparada. Rio de Janeiro: Zahar.

ALMOND, G. \& VERBA, S. 1989. The civic culture: political attitudes and democracy in five nations. Nova York: Sage.

AVELAR, L. 2004. Participação política. In: AVELAR, L. \& CINTRA, A. O. Sistema político brasileiro: uma introdução. Rio de Janeiro: Fundação Konrad Adenauer. São Paulo: Editora da UNESP.

AVRITZER, L. 1997. Um desenho institucional para o novo associativismo. Lua Nova, São Paulo, v. 1, n. 39, p. 149-174.

AXFORD, B., et. al. 1997. Politics: an introduction, London, Routledge. 
BAQUERO, M. 1997. O papel dos adolescentes no processo de construção democrática no Brasil. Um estudo preliminar de socialização política. Cadernos de Ciência Política. Porto Alegre, n. 8, p. 3-34, jul.

BARNES, S. et. al. 1979. Political action: mass participation in five western democracies. Beverly Hills: Sage Publications.

BOHRNSTEDT, G.G. \& KNOKE, D. 1982. Statistics for social data analysis. New York: Peacock.

BOOTH, J. \& SELISON, M. A. 1978. Political participation in Latin America. Vol. 1: Citizen and State. Holmes \& Meyer Publishers.

CATTERBERG, G. 2004. Evalutions, referents of support, and political action in new democracies. In: International Journal of Comparative Sociology, v. 44, p. 173-198.

COHEN, J.; ARATO, A. 1992. Civil society and political theory. Cambridge, The Mit Press.

DAHL, R. 1997. Poliarquia. São Paulo: Edusp.

DALTON, R. J. \& WATTENBERG, G. M. 2001. Parties without partisans: political change in advanced industrialized democracies. Oxford: Oxford University Press, 2001.

DELLA PORTA, D. 2003. Introdução à ciência política. Lisboa: Estampa, 2003.

2008. Paths to february 15 protest: social or political determinants? To be published in Dieter Rucht and Stefaan Walgrave (eds), Protest Politics Anti-war mobilization in Western Democracies. Disponível em www.lse.ac.uk/Depts/global/PDFs/ Peaceconference/dellaporta.doc. Acesso em dezembro de 2008.

DINIZ, E. 1985. A transição política no Brasil: uma reavaliação da dinâmica da abertura. Dados, Rio de Janeiro, v. 28, n. 3, p. 329-46, out.

INGLEHART, R. 1977. The silent revolution. Princeton: Princeton University Press.

1990. Cultural shift in advanced industrial society. Princeton: Princeton University Press.

2001. Modernización y posmodernización: el cambio cultural, economico y político en 43 sociedades. Madrid: Centro de Investigaciones Sociológicas.

INGLEHART, R. \& CATTERBERG, G. 2002. Trends in political action: the development trend the post-honeymoon decline. In: International Journal of Comparative Sociology IJCS, v. 43 (3-5), p. 300-316.

INGLEHART, R. \& WELZEL, C. 2005. Modernization, cultural change, and democracy: the human development sequence. Cambridge: Cambridge University Press.

KINZO, M. D. 2001. A democratização brasileira: um balanço do processo político desde a transição. São Paulo em Perspectiva, São Paulo, v. 15, n. 4, 3-12, out/dez.

MARTINS, L. 1986. The liberalization of the authoritarian rule in Brazil. In: O'DONNELL, G; SCHMITTER, P.C. \& WHITEHEAD, L. (eds.). Transitions from authoritarian rule. Baltimore: Johns Hopkins University Press.

MILBRATH, L., GOEL, M. L. 1965. Political participation. Boston: University Press of America.

NORRIS, P. 2002. Democratic phoenix: reinventing political activism. Cambridge: Cambridge University Press.

2007. Political activism: new challenges, new opportunities. In: BOIX \& STOKES. The oxford handbook of comparative politics. Oxford: Oxford University Press, p. 628-652. Disponível em http:// ksghome.harvard.edu/ pnorris/Acrobat/ Boix\&stokes-chap26.pdf. Acesso em fevereiro de 2009. 
OLSON, M. 1999. A lógica da ação coletiva. São Paulo: Edusp.

PIZZORNO, A. 1975. Condizioni della participazione política. In: PIZZORNO, A. Le radici della politica assoluta. Milano, Feltrinelli.

1985. Algum tipo diferente de diferença: uma crítica das teorias da escolha racional. In: FOXLEY, A. MACPHERSON, M., O'DONNELL, G. Desenvolvimento e política e aspirações sociais. O pensamento de Albert Hirschmann. São Paulo: Vértice, p. 366-386.

PUTNAM, R. 1996. Comunidade e democracia: a experiência da Itália moderna. Rio de Janeiro: Fundação Getúlio Vargas.

2002. Solo en la bolera. Colapso y resurgimiento de la comunidade norteamericana. Barcelona: Galaxia Gutenberg.

(Org.). 2003. El declive del capital social. Barcelona: Galaxia Gutenberg, 2003.

PUTNAM, R. \& GOSS, K. A. 2003. Introducción. In: PUTNAN, R (Org.). El declive del capital social. Barcelona: Galaxia Gutenberg, pp 7-34.

RENNO, L. R. 2003. Estruturas de oportunidades políticas e engajamento em organizações da sociedade civil: um estudo comparado sobre a América Latina. In: Revista de Sociologia \& Política, 21, p. 71-82

RIBEIRO, E.A. 2007. Teoria do desenvolvimento humano, cultura política e democracia. Revista Brasileira de Informação Bibliográfica em Ciências Sociais, BIB, São Paulo, n. 64, p. 5-128.

ROKEACH, M. 1968. Beliefs, attitudes and values. San Francisco: Jossey-Bass.

SCHUMPETER, J. 1961. Capitalismo, socialismo e democracia. Rio de Janeiro: Fundo de Cultura, 1961.

STEPAN, A. (ed.). 1989. Democratizando o Brasil. Rio de Janeiro: Paz e Terra.

TOURAINE, A. 1994. Crítica da modernidade. Petrópolis: Vozes, 1994.

VERBA, S. \& NIE, N. H. 1972. Participation in America. Political democracy and social equality. New York: Harper \& How.

VERBA, S.; SCHLOZMAN, K. L.; BRADY, H. E. 1995. Voice and equality. Civic voluntarism in American politics. Harvard University Press.

WELZEL, C.; INGLEHART, R., DEUTSCH, F. S. 2005. Social capital, voluntary associations and collective action: Which aspects of social capital have the greatest 'Civic'Payoff? In: Journal of Civil Society, v. 1, n. 2, p. 121146, September. 